\section{The role of protein-53 amyloid in determining the aggressive- ness of basal cell carcinoma regulated by interleukin-6, myeloid cell leukemia-1 and basic fibroblast growth factor}

Prasetyadi Mawardi, ${ }^{1}$ Handono Kalim, ${ }^{2}$ Kusworini Handono Kalim, ${ }^{3}$ Loeki Enggar Fitri, ${ }^{4}$

Karyono Mintarjo, ${ }^{5}$ Ambar Mudigdo, ${ }^{6}$ Oyong Oyong, ${ }^{6}$ Brian Wasita $^{6}$

${ }^{1}$ Dermatovenereology Department, Medical Faculty of Sebelas Maret University/Dr. Moewardi Public Hospital, Surakarta;

${ }^{2}$ Internal Medicine Department, Faculty of Medicine Brawijaya University/dr. Saiful Anwar Public Hospital, Malang; ${ }^{3}$ Clinical Pathology Department, Faculty of Medicine Brawijaya University/dr. Saiful Anwar Public Hospital, Malang; ${ }^{4}$ Parasitology Department, Faculty of Medicine Brawijaya University/dr. Saiful Anwar Public Hospital, Malang; ${ }^{5}$ Pathology Department, Faculty of Medicine, Brawijaya University/dr. Saiful Anwar Public Hospital, Malang; ${ }^{6}$ Pathology Department, Medical Faculty of Sebelas Maret University/Dr.

Moewardi Public Hospital, Surakarta, Indonesia

\section{Abstract}

Basal cell carcinoma (BCC) is a common malignant skin tumor that rarely metastasized, although it is often locally destructive and aggressive. The amyloid in $\mathrm{BCC}$ is resulted from degenerated epithelial cell through apoptosis caused by activation of p53. Interleukin-6, MCL-1 and bFGF are inflammatory mediators which have important role in angiogenesis. To prove that high expression of p53 amyloid is related to aggressiveness of $\mathrm{BCC}$ via the regulation of IL-6, MCL-1 and bFGF expression. Archived specimens from 51 cases diagnosed with Primary BCC. We performed immunohistochemical staining for IL-6, MCL-1, bFGF expression and p53 amyloid deposit. There was a significant difference in the expression of p53 $(\mathrm{p}=0.04)$, amyloid deposits $(p=0.015)$, P53 amyloid deposits $(\mathrm{p}=0.038)$, IL-6 $(\mathrm{p}=0.040)$, MCL-1 ( $\mathrm{p}=$ $0.032)$, bFGF $(p=0.044)$ in A BCC compared with NA BCC. There were a significant association between MCL-1 and bFGF $(\mathrm{p}=0.07)$ and $\mathrm{p} 53$ amyloid with bFGF $(\mathrm{p}=$ 0.051). p53 amyloid, IL-6, MCL-1 and
bFGF have an important role in BCC aggresivity.

\section{Introduction}

Basal cell carcinoma (BCC) is a very common malignant skin tumor that rarely metastasizes, even though is often locally aggressive. Several factors, like a large size (more than $3 \mathrm{~cm}$ ), face localization, exposure to ultraviolet rays, histological variants, infiltration level and perineural or perivascular invasion, are associated with a more aggressive clinical course. ${ }^{1}$ Although it rarely metastasizes, $\mathrm{BCC}$ can cause significant damage due to its local and aggressive recurrences. ${ }^{2}$ p53 is activated upon the induction of DNA damage to either arrest the cell cycle or to induce apoptosis. However, when mutated, p53 is no longer able to properly accomplish these functions. Apparently, appropriate p53 functioning is crucial for the suppression of tumor development. ${ }^{3}$ The p53 gene is not reactive in cells where DNA is undamaged. When there is DNA damage, the gene suspends the cell cycle until the damage can be repaired. The p53 gene is not reactive in cells where DNA is undamaged. When there is DNA damage, the gene suspends the cell cycle until the damage can be repaired. If there is a mutation in p53, the cell cycle continues unrestrained and damaged DNA is reproduced, leading to uncontrolled cell proliferation and cancerous tumors. ${ }^{4}$ The existence of amyloid deposits in BCC has been found in previous studies. The frequency of secondary amyloidosis in BCC varies from $50 \%$ to $75 \%$ in the literature. In the past, the origin of amyloid in BCC was thought to be derived from degenerated epithelial cells following apoptosis. ${ }^{5}$

This study aimed to investigate the differences in the immunohistochemical expression of p53, amyloid deposits, IL-6, MCL-1 and bFGF in aggressive BCC. The expression of these markers was associated with clinicopathological features such as age, gender and anatomical sites of the lesions, as well as aggressive vs nonaggressive forms of BCC.

\section{Materials and Methods}

Archived specimens from 51 cases diagnosed with primary BCC were collected from December 2014 to May 2016 at the Dr. Moewardi Public Hospital in Surakarta, Central Java, Indonesia. Clinical findings such as age, gender and tumor localization were obtained from medical records. Specimens were reevaluated independently
Correspondence: Prasetyadi Mawardi, Departement of Dermatovenerology, Dr. Moewardi General Hospital, Surakarta, Indonesia.

Tel.: +62271 634848 - Fax: +62271 634848 . E-mail: prasetyadimawardi@yahoo.com

Key words: basal cell carcinoma, basic fibroblast growth factor, protein-53 amyloid, interleukin-6, myeloid cell leukimia-1

Contributions: The authors contributed equally.

Conflict of interest: the authors declare no potential conflict of interest.

Received for publication: 1 February 2019 Accepted for publication: 6 February 2019.

This work is licensed under a Creative Commons Attribution-NonCommercial 4.0 International License (CC BY-NC 4.0).

(C) Copyright P. Mawardi et al., 2019

Licensee PAGEPress, Italy

Dermatology Reports 2019; 11(s1):8012

doi:10.4081/dr.2019.8012

by two expert pathologists who agreed on all specimens involved in the study. Histopathological types of BCC were determined and histopathological classification of the lesions was performed according to the criteria proposed by Dixon and Jacobs et al. ${ }^{6,7}$ In order to detect $\mathrm{p} 53$ protein expression in BCC specimens, we performed immunohistochemical staining as follows. Initially, we chose adequately represented BCC paraffin blocks, and then the blocks were deparaffinized and dehydrated. Strongly positive control slides were used in each run of the immunochemical staining procedure for each protein, i.e. p53 (breast carcinoma), IL-6 (tonsil) and bFGF (brain tissue). Expression measurement of p53, Il6, MCl-1, and bFGF and p53 amyloid used J-Image (open access). Amyloid deposite were assessed with the Congo Red staining procedure. Statistical analyzed with Kruskal Wallis and Mann Whitney method for comparing data, and Pearson's chi square for correlation studied.

\section{Results}

From the 51 BCC pathologic's slides that underwent histopathological examinations, thirteen patients were excluded. In this study we found predominantly females than males $(55.3 \% ; 44.7 \%)$. The age range of the patients were 41-90 years old, with the most common occupation was farmer (53.6 \%) and housewife (26.7 \%). According to the duration of illness, most patients had symptom for more than 3 years 
and affect people over 50 years old.

Based on the biological aspect $\mathrm{BCC}$, this study has found aggressive BCC (A BCC) is more dominant than nonaggressive $\mathrm{BCC}$ (NA BCC) with $65.8 \%$ and $34.2 \%$ respectively. All patients were divided based on site predilection according to the Baker protocol (2007). About $73.7 \%$ tumor site predominant in the midface followed by the upperface $(15.8 \%)$ and the lowerface $(10.5 \%)$. There was significant difference between aggressive BCC and nonaggressive $\mathrm{BCC}$ upon tumor site predilection $(\mathrm{p}=$ 0.033 ). Based on histopathological features, this study found 6 (six) subtype of BCC, which are nodular, basosquamous, morpheaform, mixed, infiltrative and superficial subtype. Nodular and morpheaform BCC were more dominant subtype than others. Expression of p53 was found $76.3 \%$ in this study. This expression is higher in A $\mathrm{BCC}$ rather than in NA BCC $(47.4 \%$ vs $28.9 \%$ ). There was a significant difference in the expression of $\mathrm{p} 53$ positive 1 and $2 \mathrm{~A}$ BCC compared with NA BCC ( $\mathrm{p}=0.04)$. Amyloid deposits was found in $89.4 \%$, in which the amyloid deposits in A BCC is higher than NA BCC (60.5\% vs $28.9 \%)$. There was a significant difference in positive amyloid deposits 3 and 4 at A BCC compared to NA BCC ( $p=0.015)$. P53 amyloid deposits was found in $65.8 \%$, in which p53 amyloid deposits in A BCC higher than that in NA BCC (42.1\% vs $23.7 \%$ ), and it showed statistically significant difference between A BCC and NA BCC ( $p=$ 0.038) (Figure 1). Expression of IL-6 was found in $89.4 \%$ (Table 1). Expression of IL6 in A BCC was twice higher than NA BCC $(65.7 \%$ vs $34.3 \%)$. The difference between expression of IL- 6 positive 2 and 3 in A BCC and NA BCC was statistically significant ( $p$ $=0.040)$. The expression of MCL-1 was found in $65.8 \%$ sample, in which A BCC $44.7 \%$ and NA BCC $21.1 \%$. The differences between MCL-1 positive 2 and 3 in A BCC compared to NA BCC was statistically significant $(\mathrm{p}=0.032)$. While the expression of bFGF was found in $89.4 \%$ sample, in which A BCC $57.9 \%$ and NA BCC $31.5 \%$. The differences between expression of $\mathrm{bFGF}$ positive 2 and 3 in A BCC compared to NA BCC was statistically significant $(p=0.044)$. The study also found a significant association between MCL-1 expression and bFGF ( $p=$
0.07 ) and contigency coefficient (cc) 0.34 This study also found a close correlation between p53 amyloid with bFGF ( $p=0.051)$ and contigency coefficient (cc) 0.45 .

\section{Discussion}

Basal cell carcinoma is the most common cutaneous cancer, with increasing prevalence especially in lighter skinned individuals or in the Caucasian population. Several studies have shown that BCC is more often found in men compared to women. This may reflect a higher rate of sun exposure in males because of their employment pattern. ${ }^{8}$ However, in this study, BCC was found more often in women than in men, i.e. $55.3 \%$ vs. $44.7 \%$, respectively. The incidence in women is increasing due to changing fashions in clothing and increased time spent outdoors for recreational or occupational reasons. Based on occupation, this study found that farmers are more frequently affected BCC than others. UV radiation, especially UVB, is responsible for the majority of cutaneous damage and is believed to be the primary risk factor driving tumorigenesis in $\mathrm{BCC}{ }^{9}$ The present study found more BCC in the midface region than in the other areas; $\mathrm{BCC}$ in the midface region is more aggressive. As stated by Baker (2007), the midface area covers the glabella to the sub-nasal area. ${ }^{10}$ According to the histological findings, the nodular, morpheic and basosquamous BCC subtypes were more frequent than the other subtypes in this study. The most common subtype (with an estimated 60\%-75\% prevalence overall) is the nodular (or nodulocystic) subtype, which is especially common in the head and neck area. ${ }^{11}$ In this study, the nodular and morpheic BCC subtypes comprised $52.6 \%$ of all samples.

Basal cell carcinoma is a multifactorial disease in which both environmental factors and host genetic factors are implicated in carcinogenesis. In this study, $47.4 \%$ nuclear positivity for p53 was found in all groups. Khodaeilani et al. (2013) found a p53 expression rate of $67.7 \%$, which was higher than in this study. ${ }^{12}$ The tumor suppressor p53 regulates genome integrity. It is frequently mutated in all types of human cancer, making p53 a main factor in cancer development. ${ }^{13}$ Based on amyloid deposits, this study found that most BCC $(92.1 \%)$ had amyloid deposits. Several previous studies have found that secondary amyloidosis in BCC varies from $50 \%$ to $75 \%$. In the present study, the origin of amyloid deposits in BCC is thought to be derived from degenerated epithelial cells via apoptosis. If the correlation between p53 expression and amyloid obtained a statistically

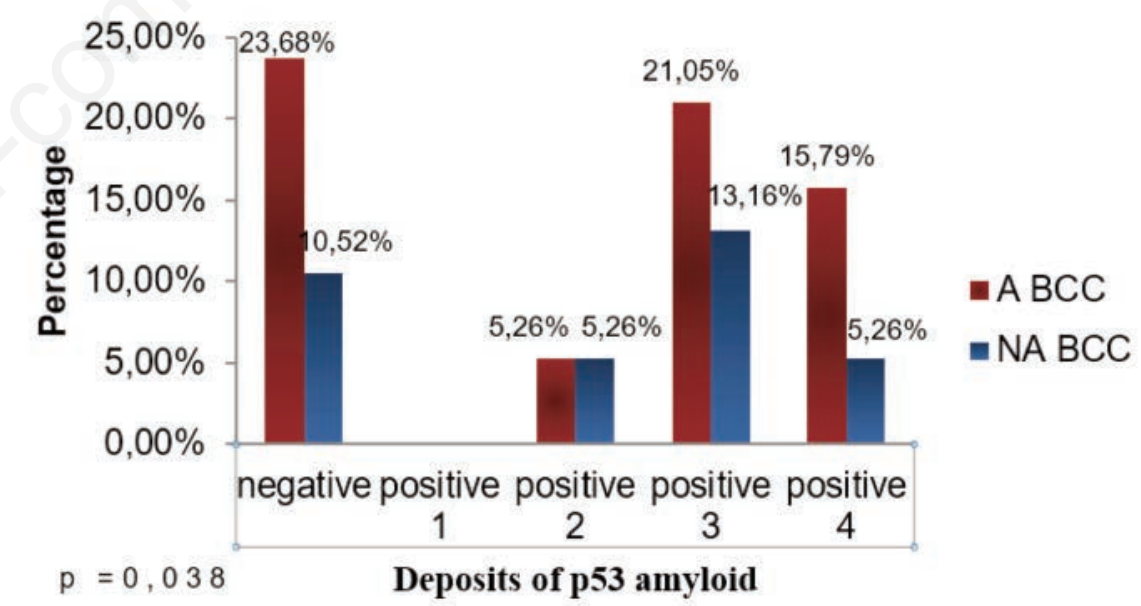

Figure 1. Deposits value of $\mathrm{p} 53$ amyloid related to BCC aggressivity.

Table 1. Protein 53 expression, Amyloid deposite, p53amyloid, IL-6, MCL-1 and bFGF related BCC aggressivity.

\begin{tabular}{lccccccc} 
Type & N & P53 & Amyloid & p53amyloid & IL-6 & MCL-1 \\
A BCC & 25 & $18(47.4 \%)$ & $23(60.5 \%)$ & $16(42.1 \%)$ & $23(60.5 \%)$ & $17(44.7 \%)$ & $22(57.9 \%)$ \\
NA BCC & 13 & $11(28.9 \%)$ & $11(28.9 \%)$ & $9(23.7 \%)$ & $11(28.9 \%)$ & $8(21.1 \%)$ & $12(31.5 \%)$ \\
\hline Total & 38 & $29(76.3 \%)$ & $34(89.4 \%)$ & $25(65.8 \%)$ & $34(89.4 \%)$ & $25(65.8 \%)$ & $34(89.4 \%)$ \\
\hline
\end{tabular}


significant difference, it means there is a difference in the role of $\mathrm{p} 53$ in determining the aggressiveness of A BCC and NA BCC $(\mathrm{p}<0.05)$. Amyloid fibril deposition has been described in patients with malignant disease. It is more frequently seen in hematological neoplasms and has also been noted in patients with solid tumors. This study also found higher IL-6, MCL-1 and bFGF expression in A BCC than in NA BCC. Proinflammatory cytokines induce angiogenesis. The Bcl-2 protein family, including MCL-1, is critical to the regulation of the intrinsic apoptotic pathway and the elimination of cells affected by oncogenic mutations in various human tissues, including the epidermis. ${ }^{14}$ Enhancing IL-6 expression also induced MCL-1 expression. MCL-1 is an anti-apoptotic protein that is essential for the survival of multiple cell lineages and is highly amplified in human cancer. Under physiological conditions, the MCL-1 expression is tightly regulated at multiple levels, involving transcriptional, post-transcriptional and post-translational processes. Beta-FGF or FGF-type 2 is the most important angiogenic factor, along with VEGF, and stimulates angiogenesis, which is a sequence of cellular events comprising vascular initiation, formation, maturation, remodeling, and regression, which are tightly controlled to meet tissue requirements. Angiogenesis has an important role in the development and progression cancer. ${ }^{15}$

\section{Conclusions}

Given the results of this study, a midface location of BCC is significantly more aggressive than $\mathrm{BCC}$ at other sites. This study also found BCC more frequently in females than in males. The expression of p53 amyloid was significantly different in A BCC and NA BCC, but was associated with amyloid deposits; $\mathrm{p} 53$ amyloid role in determining aggressiveness between A BCC vs. NA BCC was significantly different. The expression of MCL-1 and bFGF was significantly higher in A BCC than in NA BCC.

\section{References}

1. Pilloni L, Bianco P, Manieli C, et al. Immunoreactivity for alpha-smooth muscle actin characterizes a potentially aggressive subgroup of little basal cell carcinomas. Eur J Histochem 2009;53: 113-6.

2. Epstein EH. Basal cell carcinomas: attack of the hedgehog. Nat Rev Cancer 2008;8:743-54.

3. Ghaderi R, Haghighi F. Immunohistochemistry assessment of p53 protein in Basal cell carcinoma. Iran $\mathrm{J}$ Allergy Asthma Immunol 2005;4:16771.

4. George P. P53 how crucial is its role in cancer?. Int J Curr Pharm Res 2011;3:19-25.

5. Chen CC, Chen CL. Clinical and histopathologic findings of superficial basal cell carcinoma: a comparison with other basal cell carcinoma subtypes. J Chin Med Assoc 2006;69:364-71.

6. Dixon AY, Lee SH, McGregor DH. Factors predictive of recurrence of basal cell carcinoma. Am J Dermatopathol 1989;11:222-32.

7. Jacobs G, Rippey J, Altini M.
Prediction of aggressive behavior in basal cell carcinoma. Cancer 1982; 49:533-7.

8. Situm M, Buljan M, Bulat V, et al. The role of uv radiation in the development of basal cell carcinoma. Coll Antropol 2008;32:167-70.

9. Avci G. An overview on basal cell carcinoma. 2011. In: Skin Cancer Overview [Internet]. Intech. Available from: https://http://www.intechopen. com/books/skin-cancer-overview/anoverview-on-basal-cell-carcinoma.

10. Baker SR. Reconstruction of the nose in: Local Flap in Facial Reconstruction. Edisi ke2. Michigan USA: Mosby; 2007.

11. Kraft S, Granter SR. Molecular pathology of skin neoplasms of the head and neck. Arch Pathol Lab Med 2014;138: 759-87.

12. Khodaeiani E, Fakhrjou A, Amirnia M, et al. Immunohistochemical evaluation of p53 and Ki67 expression in skin epithelial tumors. Indian J Dermatol 2013;58:181-7.

13. Lasagna-Reeves CA, Clos A, CastilloCarranza D, et al. Dual role of p53 amyloid formation in cancer; loss of function and gain of toxicity. Biochem Biophys Res Commun. 2013;430:9638.

14. Burke MT, Morais C, Oliver KA, et al. Expression of Bcl-xL and Mcl-1 in the nonmelanoma skin cancers of renal transplant recipients. Am J Clin Pathol. 2015;143:514-26.

15. Spinelli FM, Vitale DL, Demarchi G, et al. The immunological effect of hyaluronan in tumor angiogenesis. Clin Trans1 Immunology 2015;4:e52. 